\title{
Evaluation of speakers with foreign-accented speech in Japan: the effect of accent produced by English native speakers
}

\author{
Chiharu Tsurutani* \\ Arts, School of languages and Linguistics, Griffith University, Brisbane QLD 4121, Australia
}

(Received 9 December 2011; final version received 21 May 2012)

Foreign-accented speakers are generally regarded as less educated, less reliable and less interesting than native speakers and tend to be associated with cultural stereotypes of their country of origin. This discrimination against foreign accents has, however, been discussed mainly using accented English in English-speaking countries. This study investigates the attitudes of Japanese people towards foreign-accented Japanese and their difference depending on the area of their residency, which will provide a valuable comparison to previous studies on the attitude towards foreign accent. Two groups of participants, one living in a metropolitan area and the other in a rural area, listened to a short Japanese passage spoken by Japanese native speakers and non-native (native English) speakers, and evaluated what they thought of each speaker's likely personality, job and social status. The participants rated native speakers higher than non-native speakers in competence and integrity, and rated both types of speakers equally only in social attractiveness. The results show that despite some admiration of and respect for western culture in Japanese society, when their judgement is based on auditory speech, Japanese participants evaluate fluent native speakers of Japanese more favourably than foreign-accented speakers.

Keywords: foreign-accented speech; accentedness: Japanese language; non-native speakers; language attitude

\section{Introduction}

As globalisation and internationalisation progress, the need to communicate in languages other than one's own has become almost inevitable. As a consequence, the opportunity to communicate with non-native speakers has increased dramatically in many countries. How are these non-native speakers viewed by native speakers of the country where they reside? In English-speaking countries, a negative view towards foreign-accented speakers is witnessed frequently in everyday life and reported in various studies (Ball 1983; Bresbahan et al. 2002; Callan and Gallois 1983; Munro, Derwing, and Sato 2006; Riches and Foddy 1989). Although regional native speaker accents such as African-American English and British Cockney are also a target of prejudice (Lippi-Green 1994), in-migrant minority languages tend to attract the most AQ2 negative attitudes from majority language communities (Garret 2010). In general, majority language communities regard foreign-accented speakers as less educated, less reliable and less interesting than a native English speaker. Studies have identified the tendency for English native speakers to rate people speaking English with foreign

*Email: c.tsurutani@griffith.edu.au 
accents low in competence but more highly in social attractiveness (Eisenchlas and Tsurutani 2011; McKenzie 2010).

Evidence of discriminatory attitudes towards accented speakers has been reported widely in America, Australia and other western societies (Bresbahan et al. 2002; Eisenchlas and Tsurutani 2011; Lindemann 2003; Lippi-Green 1994; Rubin 1992). The stronger the perceived accent, the more negative the attitude of listeners (Callan, Gallois, Forbes 1983; Lev-Ari and Keysar 2010). These attitudes are partly attributed to accent stereotyping, i.e. stereotyping of accented speakers in the society (Munro 2003). They originate partly from the accented speaker's difficulty in actually processing the language due to non-standard pronunciation or rhythm, thus producing speech with which the listener is unfamiliar. It is known that familiarity with a particular accent accommodates comprehension and intelligibility (Gass and Varonis 1984). People tend to favour accents familiar to them, which is observed also in regional accents (Long 1999). If listeners negatively evaluate speech that is intelligible enough for them to comprehend, this evaluation is considered to stem from accent stereotyping. Prejudice and discrimination against unfamiliar appearance and speech seem to be hard to eradicate and this discriminatory attitude has been observed in all societies.

However, the worldwide spread of English created the notion of English as a lingua franca among people from different nations where English is a first language, second language or foreign language (McKenzie 2010). It also suggested, in linguistic terms, that no one variety of English is better than any other (Kirkpatrick, Deterding, and Wong 2008). Discrimination against accented speech has therefore been a concern, inspiring a trend to promote tolerance towards accented speech (Jenkins 2000). Foreign-accented speech is certainly a significant part of accented speech and hence requires our attention. Foreign accent discrimination has, however, been discussed mainly in English-speaking countries where non-native speakers are common and social issues related to them are rife due to the long history of migration to English-speaking countries (Munro 2003). We need to better understand native-speaker attitudes towards foreign accents in other languages to complement the existing attitudinal studies.

Japanese was chosen for this comparative study as its history of migration contrasts with that of the English-speaking west. Study of accented speech in Japan has been conducted only on Japanese people's perceptions of English dialectal differences (Chiba, Matsuura, and Yamamoto 1995; McKenzie 2008, 2010), accented English (Cargile and Giles 1998; Tokumoto and Shibata 2011; Yashima, ZenukNishide, and Shimizu 2004) and Japanese regional dialects (Long 1999; Morris 2010). In Japan, Japanese language accent has many regional variations that developed through the strict management of small agricultural villages under feudalism. Those who spoke regional variations felt inferior to those in the capital, the national centre of power, who spoke the national standard language until late in the twentieth century (Shibatani 1990). However, the movement of people and mass communication have fostered the spread and levelling of variations on the common language to achieve the equal status of regional variations with the national standard AQ3 (Ball 2004; Iino et al. 2003; Shibatani 1990). These studies have also identified that while variations on the national standard tend to attract respect, native speakers still favour familiar accents.

Negative attitudes towards foreign accents, which seem, at first, fundamental to human nature, may result from economic disparity or the perceived threat of 
indigenous people towards newcomers in a particular society. Japan has been a mono-racial country for centuries, and foreign migrants have never been visibly dominant due to the country's history and strict migrant policy. Currently 2.2 million foreigners live in Japan, but roughly $60 \%$ of them are Korean and Chinese people who have been long-term residents and live as fluent native speakers of Japanese. Even though some of these Korean and Chinese citizens have a slight foreign accent, they are not easily recognised as foreigners since their physical appearance does not distinguish them.

The remaining one million non-Japanese residents are only a small portion $(<1 \%)$ of Japan's population of 120 million, and are concentrated in big cities. Although the number of foreign residents is on the rise and the number of international students is at an historical high of 123,829 in 2010 (Japan Student Service Organization 2010), compared with other migration nations such as Australia, where migrants comprise a quarter of the population, foreigners are still a very small minority in Japan.

Japan's mono-racial society has tended to admire western culture and westerners since it was opened to the west after the Meiji restoration in 1868 (Tipton 2008; Willcock 2008). Despite a sense of national pride and cultural superiority long evident through terms such as 'wakon yosai' (Japanese sprit and Western technology)

AQ4 in the nineteenth century (Sugimoto 2003) and establishment of the Japan Foundation in the early 1970s to promote Japanese language and culture abroad (Tipton 2008), inside Japan ordinary Japanese citizens have not really expected foreigners to speak Japanese when they first meet on the street. The concept of Nihonjinron (theories of Japanese) claiming that Japanese language and culture are unique (Gottlieb 2005; Suzuki 1978) upholds that only those who are born to parents of Japanese blood, grow up in Japanese society and speak Japanese from childhood can ever really understand the language and how it works in Japanese society (Carroll 2001). Some still hold this view even though around the world there are millions of non-Japanese people who do not satisfy all three criteria but are highly competent in Japanese language (Gottlieb 2005).

This socio-historical background suggests that Japanese people can have very positive attitudes towards the foreign accents of westerners speaking Japanese, particularly in rural regions where foreigners from western countries are far fewer than in metropolitan areas; $18 \%$ of Japan's foreign residents are concentrated in Tokyo while regional prefectures accommodate $<2.5 \%$ [Homusho (Ministry of AQ5 Justice) 2002]. Two or three decades ago, it was uncommon to meet a westerner who could speak Japanese, whether non-fluent or fluent, and thus westerners who spoke Japanese were a novelty and were respected.

The recently increased presence of foreigners in Japan - including many more who have some, or considerable, Japanese language ability - has likely helped to shift Japanese people's attitudes towards non-native speakers of Japanese. If so, the shift may be evident towards western people who are visibly non-Japanese and therefore may be particularly evident in large cities where many westerners are seen constantly. Japanese television today screens westerners speaking fluent Japanese or at nearnative level, but chances for Japanese people to have direct contact with westerners are still mostly limited to particular areas in big cities or at famous travel destinations that foreigners visit in Japan.

Understanding of local attitudes towards speakers with a foreign accent has particular significance for nations such as Japan that plan to increase their number of 
foreign residents (Tokyo Shimbun 2011). The researcher therefore conducted a study of the perceptions of Japanese people in both a metropolitan area and a small town in Japan to observe differences and similarities in their attitudes towards foreignaccented speech by westerners speaking Japanese. I recognised two factors that could be at work in both types of locations. First, the traditional view that Japanese is a unique language too difficult for foreigners to learn could bring out positive evaluation of foreigners who can speak Japanese. Second, Japanese people's increasing exposure to Japanese-speaking foreigners could deepen familiarity with foreigners' accents, which could also affect the evaluations by participants in our study.

The present study addresses the following questions:

(1) Do Japanese people have a positive attitude towards foreign-accented speech by English speakers and more particularly do they evaluate such speakers highly in terms of Japanese language Competence?

(2) Does the strength of the foreigner's accent affect the listener's evaluation?

(3) Do attitudes towards foreign-accented speech differ between metropolitan and rural areas, given the different opportunities within these areas to communicate with non-native speakers? If so, is the attitude of people in rural areas more positive than of people in metropolitan areas?

This study concerns foreign accents produced by native speakers of English whom Japanese people generally identify more strongly with 'foreign' than they do with foreigners from Asian countries. Discrimination by Japanese towards the background of non-Japanese people (e.g. Asians vs. westerners) is beyond the scope of this study. The focus of this study is on the relationship between the degree of accentedness of non-native speakers' foreign accents when speaking Japanese and native listeners' attitudes towards these accents. To eliminate factors irrelevant to the purpose of the study and enable its focus on appreciation of accent, speakers from the same language background, English, and same gender, male, were chosen as nonnative speakers.

\section{Methods \\ Participants}

A total of 124 university students comprising $66(M=14, F=52)$ from a small city where foreign visitors are rare (Ube city in Yamaguchi prefecture) and $58(M=7$, $F=51$ ) from Tokyo participated in the study. All had given prior agreement to participate in the study. They were classified as Group R (Rural) and Group M (Metropolitan-Tokyo). The students in Group $\mathrm{R}$ were majoring in dietetics at a college and had little opportunity for personal communication with westerners in their everyday life, while the students in Group $M$ were majoring in subjects related to international relations in Tokyo and presumably had interest and need to communicate with non-native speakers. The nature of courses meant they each had more female than male students. However, since the gender imbalance of the two groups was similar, it was considered to be appropriate in terms of group comparison for this study. The participants' ages ranged from 18 to 20 years. 


\title{
Materials
}

Participants were asked to listen to readings by native and non-native male speakers. The reading material was a short passage, a Japanese translation of 'The North Wind and the Sun', which is known for testing English pronunciation of English L2 learners. The researcher modified the translated passage so that it contained phonemes and sound sequences (e.g. the contrast of long and short vowels and consonants) phonetically difficult for native English speakers. A romanised version of the passage follows with underlining of geminate consonants, long vowels, contracted sounds and word initial ' $t s u$ ' and ' $f u$ ' that are hard for non-native Japanese speakers to pronounce.

\begin{abstract}
Kitakaze to taiyoo ga dochiraga tsuyoika arasoimashita. Sonotoki, hitori no tabibito ga michi o kudatte kuruno o mite, taiyoo ga "Anohito no uwagi o totta hoo ga tsuyoi to ierunjanaika. Mazu kimikara da" to itte kumo no ushironi kakuremashita.

Kitakaze wa tabibito ni mukatte byuu byuu kaze o fukitsukemashita. Shikashi, kitakaze ga fukebafukuhodo, gyakuni tabibito wa uwagi o shikkarito osaetsuke tobasarenaiyooni shimashita. Kekkyoku, kitakaze wa akiramerushika nakattanodesu.
\end{abstract}

This passage translates as follows:

The north wind and the sun argued which of them has greater strength. Then, the sun saw a man traveling down a road far below. 'As a test of strength, let us see which of us can take the coat off of that man. You go first'. said the sun and hid behind the cloud. The wind blew so hard, but the harder the wind blew down the road, the tighter the shivering man clung to his coat.? In the end the north wind could do nothing but give up.

\section{Speakers of stimulus tape}

Six male speakers, of whom two were native Japanese speakers, two were non-native speakers with a mild accent and two were non-native speakers with a heavy accent, recorded the Japanese passage. Two speakers were used for each group to try to minimise the influence of characteristics of a particular voice on listeners' judgement. At the time of the study all six speakers were university academics or researchers in Japan and Australia. The four non-native speakers were all native Australian and British English speakers who had lived in Japan for more than a few years.

The strength of accent of the six speakers was classified according to the judgement of three experienced native-speaking Japanese language teachers. These judges marked the reading of the four non-native speakers using a Likert scale with potential responses ranging from 1 (native-like) to 9 (non-native-like). Speech with an average score below 5 was regarded as being slightly accented, and an average score above 5 was regarded as a heavy accent. The language background of the speakers are presented in Table 1.

Recordings of the readings were made in a sound-treated room with high-fidelity audio equipment. Speech rate and pitch range data were also provided since they could affect the listeners' judgements of each speaker's personality. All speakers read the passage at a similar speed, taking from 48 to 61 seconds (average speed 53 seconds). Heavily accented speech was perhaps inevitably slower than the average. Pitch range differed across speakers from 78 to $178 \mathrm{~Hz}$, as seen in Table 1. Since the two levels of non-native speakers had both narrow and wide pitch range, the effect of pitch range was minimised. 
Table 1. Voice characteristics of the six speakers.

\begin{tabular}{|c|c|c|c|c|c|c|}
\hline & $\begin{array}{l}\text { Speakers' } \\
\text { L1 }\end{array}$ & Age & $\begin{array}{c}\text { Years of residence } \\
\text { in Japan }\end{array}$ & $\begin{array}{l}\text { Accent } \\
\text { strength }\end{array}$ & $\begin{array}{l}\text { Reading duration } \\
\text { (seconds) }\end{array}$ & $\begin{array}{l}\text { Pitch range } \\
(\mathrm{Hz})\end{array}$ \\
\hline $\mathrm{S} 1 *$ & $\begin{array}{l}\text { Aus. } \\
\text { English }\end{array}$ & 53 & $2.5^{*}$ & 2.3 mild & 51 & $81(177-96)$ \\
\hline $\mathrm{S} 2$ & Japanese & 53 & - & 1 & 49 & $174(251-77)$ \\
\hline S3 & $\begin{array}{l}\text { Aus. } \\
\text { English }\end{array}$ & 42 & 14 & 4 mild & 54 & $162(228-66)$ \\
\hline S4 & $\begin{array}{l}\text { Aus. } \\
\text { English }\end{array}$ & 39 & 9 & 6.3 heavy & 55 & $137(214-77)$ \\
\hline S5 & $\begin{array}{l}\text { Brit. } \\
\text { English }\end{array}$ & 36 & 2 & 8 heavy & 61 & $78(168-70)$ \\
\hline S6 & Japanese & 43 & - & 1 & 48 & $168(259-91)$ \\
\hline
\end{tabular}

*S1, a Japanese language teacher in Australia, was judged to have only a weak accent despite his short period of residence in Japan.

\section{Procedure}

Recordings of the six short readings were presented to the participants in their subgroups - R1 and R2 in Ube and M1 and M2 in Tokyo after one of their university classes. The participants were asked to listen to the recordings and to try to imagine each speaker's personality. They were not told whether the speakers were foreigners or not. The recordings were presented in a different random order to the four subgroups in an attempt to reduce order effects (Table 2).

At the beginning of the judgement task, the first 5 seconds of each speaker's recording was played to give listeners some idea in advance about the speakers. Then, the CD was played and stopped after each speaker's segment and the participants were given 30 seconds to rate the speaker on accent strength using a seven-point semantic differential scale with anchors of 'not at all' (1) and 'very' (7). The scale included 13 personality traits, in random order, that fall under the categories of 'competence', 'integrity' and 'social attractiveness' (Lambert 1967):

Competence [competent, knowledgeable, intelligent, confident]

Integrity [serious, sincere, organized, enthusiastic]

Attractiveness [kind, patient, friendly, cool, entertaining]

Open-ended questions for participants to answer after listening to and rating each speaker asked participants to indicate their perception of the speaker's likely occupation and to identify his native language. The entire procedure took approximately 15 minutes to complete for all six readers.

Table 2. Order of presentation to the four subgroups.

\begin{tabular}{lc}
\hline Group size (Number of participants) & Order \\
\hline Group Metropolitan 1 (40) & Order 1 \\
Group Metropolitan 2 (18) & Order 2 \\
Group Rural 1 (21) & Order 1 \\
Group Rural 2 (45) & Order 2 \\
\hline
\end{tabular}




\section{Results and analysis}

The results are presented separately for the two groups of participants: Group $M$ in Tokyo and Group R in Ube. As noted above, each group's two sub-groups, M1 and $\mathrm{M} 2$, and $\mathrm{R} 1$ and $\mathrm{R} 2$, listened to the stimuli in a different presentation order. The correlation scores between $\mathrm{M} 1$ and $\mathrm{M} 2$ and R1 and R2 were 0.648 and 0.840 $(p=0.01)$. Thus, there was taken to be no significant difference between the two orderings, and the results of Subgroups 1 and 2 were treated as results of one group.

\section{Identifying native tongue of speakers}

An open-ended question asked participants to identify each speaker's native tongue. Tables 3 and 4 show the number and percentages of participants from both groups AQ6 who correctly identified the speakers' native tongue.

The correct identification rates for non-native speakers were $15-37 \%$, and for native speakers were 50 and $70 \%$. More than $30 \%$ of these listeners who live in the Tokyo metropolis considered that native-like speech could belong to non-native speakers for both speakers, S2 and S6, even though both actually were native speakers.

This group's participants in the small city of Ube identified the speakers' accents more accurately than did the metropolitan group in Tokyo. The Ube group's correct identification rates were between 20 and $40 \%$ for non-native speakers and 45 and $92 \%$ for native speakers.

When we consider both groups' performances, it is understandable that participants could not easily identify the native tongue of non-native speakers, whose accent is less familiar to the participants and can easily suggest several possibilities. And considering that many fluent foreign speakers of Japanese appear on TV shows across Japan, participants' overestimation of foreigners' ability is also reasonable. However, some participants in both groups of listeners found it difficult to identify whether a speaker was Japanese-native, even though speaking in the participants' own native tongue. Some participants even judged the Japanese native speaker S6 as non-native and some judged him as not even Asian. This misjudgement was contrary to our expectation. As for the other Japanese native speaker, S2, the proportion of participants who mistook him/her for a non-native speaker was higher in the Tokyo metropolitan group than in the Ube rural group (70 vs. $92.4 \%$ ).

Other identifications by the two groups overall were at similar rates of accuracy. A one-way ANOVA was used for testing to identify differences in the pattern of responses between the two groups and found these differences were not statistically significant $[F(1,10)=0.20<4.96, p=0.65]$. Overall the findings reveal that participants could not easily identify the mother tongue of a speaker from the speaker's accent when reading the selected piece. Unless participants have the necessary experience and/or linguistic knowledge about the characteristics of various foreign accents, they may well have difficulty identifying the speaker's native tongue.

The next question is whether the identity that each participant guessed for the speaker influenced how the participant appraised the speaker's accent. Although this study does not focus on discrimination between westerners and non-westerners, a small statistical test was conducted to see if there were signs of this tendency. The two groups did not present a statistically different pattern so the results shown in Tables 1 and 2 for both groups were combined. The European and Asian/African 
Table 3. Identification rates of Group M.

\begin{tabular}{lccccc}
\hline & & \multicolumn{5}{c}{ Incorrect } \\
\cline { 3 - 6 } & Correct (\%) & European & Asian & African etc. & No reply \\
\hline S1 mild & $15(27)$ & 27 & 11 & 0 & 5 \\
S3 mild & $20(34)$ & 24 & 5 & 3 & 6 \\
S4 heavy & $22(37)$ & 24 & 4 & 2 & 6 \\
S5 heavy & $9(15)$ & 16 & 19 & 7 & 7 \\
S6 Japanese & $30(50)$ & 5 & 25 & 0 & 6 \\
S2 Japanese & $40(70)$ & 10 & 2 & 0 & 6 \\
\hline
\end{tabular}

identifications of Speaker 5 who participants found to be most heavily accented (Accent score, 8) were then compared with those identifications for Speaker 1 who was found to be least accented (2.3). The numbers of responses, excluding those that AQZ were 'no reply', appear below (Table 5).

The chi-squared value of the data was 6.2, after excluding the 'no reply' responses. As the critical value is 6.64 if tested at the .01 level of significance, responses to Speaker 1 and Speaker 5 clearly show no evidence of difference between participants who thought the speaker was European and those who thought the speaker was Asian or African. The Japanese native speaker S6, who half of the participants in both groups thought was non-native, was identified as Asian rather than European by the large majority of both groups. Thus, it can be concluded that the tendency in responses of participants who thought speakers were from Asian or African countries did not differ from that in responses of participants who believed the speaker's native language was European.

\section{Personality traits and status evaluation}

Personality traits

Before the results for each group were examined, a Varimax-rotated factor analysis with Kaiser Normalization was carried out to examine whether the participants' ratings of speakers on the 13 personality traits cluster into the dimensions of competence, integrity and attractiveness. SPSS Version 18 was used for all analyses. The loadings of the 13 traits on the three factors with Eigenvalue $>1$ are shown in Table 6.

The three factors were employed as they gave the best loading. A clear clustering of the variables into the proposed dimensions was observed in attractiveness, but not

Table 4. Identification rates of Group R.

\begin{tabular}{lccccc}
\hline & & \multicolumn{5}{c}{ Incorrect } \\
\cline { 3 - 6 } & Correct (\%) & European & Asian & African etc. & No reply \\
\hline S1 mild & $20(30)$ & 19 & 19 & 2 & 6 \\
S3 mild & $25(38)$ & 27 & 9 & 1 & 4 \\
S4 heavy & $28(42)$ & 26 & 5 & 4 & 3 \\
S5 heavy & $13(20)$ & 25 & 11 & 13 & 4 \\
S6 Japanese & $30(45)$ & 14 & 20 & 1 & 2 \\
S2 Japanese & $61(92)$ & 0 & 3 & 0 & \\
\hline
\end{tabular}


Table 5. Number of participants' responses on identification of Speakers 1 and 5.

\begin{tabular}{lcc}
\hline & English/European & Asian/African \\
\hline S1 (Lightly accented speaker) & 81 & 32 \\
S5 (Heavily accented speaker) & 63 & 50 \\
\hline
\end{tabular}

in integrity and competence. The unexpected loadings could be reflections of the participants' different interpretations of the labels. 'Competent' and 'kind' had the highest loading in the wrong dimension. The participants' interpretations of 'competent (有能な yuunoo-na)' and 'kind (親切な shinsetsu-na)' seem to differ from the researcher's interpretations. The interpretation of 'kind' was also ambiguous for native-English listeners in the previous study (Eisenchlas and Tsurutani 2011). However, for the Japanese participants in this study, words related to 'competence' also seem to imply integrity; the researcher see that intelligent, knowledgeable, competent, qualities that are highly valued in Japanese society, each had a strong secondary loading. This tendency of participants to treat variables in competence the same as variables in Attractiveness was particularly strong when they judged the two native speakers. 'Being bright' seems to elicit positive evaluations in various dimensions of the Japanese participants' judgement. As a result of the factor analysis, the 13 traits were grouped into the three dimensions as follows:

Competence [knowledgeable, intelligent, confident]

Integrity [serious, sincere, organized, enthusiastic, competent, kind]

Attractiveness [patient, friendly, cool, entertaining]

\section{Influence of speaker's accent on Japanese natives' judgements}

The Group M and Group R participants' ratings for their expectations of the six speakers' personality traits are presented in Figures 1 and 2, respectively. These graphs used the average score of all participants' evaluations in each group, with 1 as

Table 6. Varimax-rotated factor analysis with 'Kaiser Normalization of participants' ratings AQ15AQ14 of speakers' characteristics' (loadings $<0.4$ are not listed).

\begin{tabular}{lccc}
\hline & \multicolumn{3}{c}{ Component } \\
\cline { 2 - 4 } & Factor 1 Integrity & Factor 2 Attractiveness & Factor 3 Competence \\
\hline Entertaining & & 0.666 & 0.566 \\
Intelligent & 0.498 & 0.405 & 0.789 \\
Confident & & & 0.660 \\
Serious & 0.839 & 0.409 & \\
Enthusiastic & 0.747 & 0.424 & 0.539 \\
Sincere & 0.787 & 0.400 & 0.655 \\
Competent & 0.636 & 0.665 & \\
Kind & 0.683 & 0.781 & 0.447 \\
Knowledgeable & 0.471 & 0.508 & \\
Patient & 0.510 & $0 \backslash 40$ & \\
Friendly & & & \\
Organised & 0.572 & & \\
Cool & & & \\
\hline
\end{tabular}




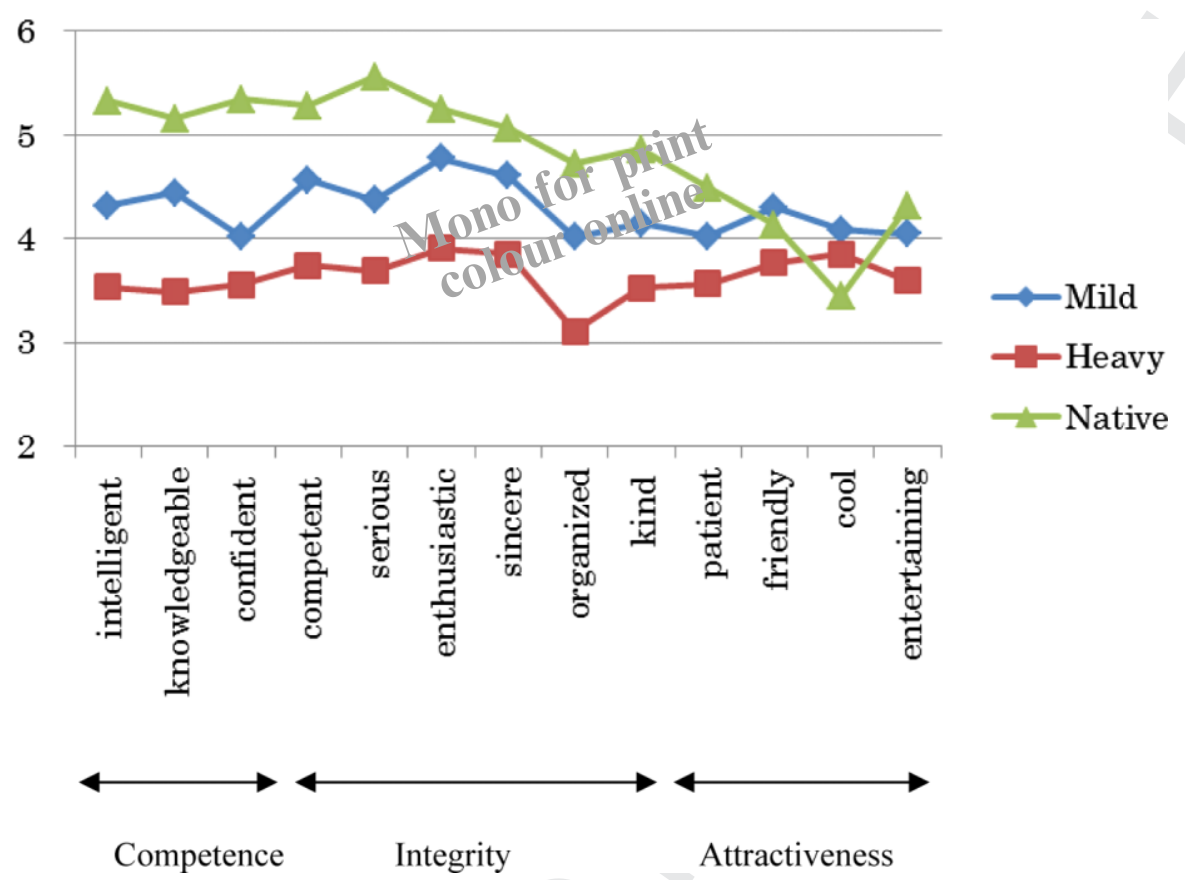

Figure 1. Group M participants' average score for each speaker's likely character.

least positive evaluation on the scale and 7 the most positive. Graphs of personality trait scores sorted by the three accent divisions appear in Figures 1 and 2 below.

Results from the two groups on the three different types of speakers were tested statistically using MANOVA, and it was found that the two groups were not significantly different in the evaluation of the three types of speakers $(p=0.674$, $0.561,0.165)$. Japanese native speaker participants' judgements was highest for the two native speakers, followed by the two speakers with mild accents and lastly the two with heavy accents. The difference between the participants' evaluations of native and non-native speakers was greater for competence and integrity than for attractiveness; this is a typical pattern of judgement towards accented speakers (McKenzie 2010; Seggie, Fulmizi, and Stewart 1982). However, the difference for Competence was smaller in Group $\mathrm{M}$ than Group $\mathrm{R}$. This may reflect the circumstances where Group $\mathbf{M}$ participants have more opportunities than Group $\mathrm{R}$ participants to meet non-native speakers who speak Japanese fluently. The information that Group M participants provided about their personal background reveals that $60 \%$ of Group M (32/59) answered they had a foreign friend who speaks Japanese, while only $6 \%$ of Group R (4/66) said so.

\section{Status evaluation - speakers' likely occupations}

The participants were asked to imagine the occupation of each speaker. Participants offered a wide range of jobs from teacher, student, sales person and [salary man to AQ8 athlete, soldier, prince and priest (see Appendix 1)]. The researcher categorised occupations as 'high' or 'low' status according to the job's requirement of a 


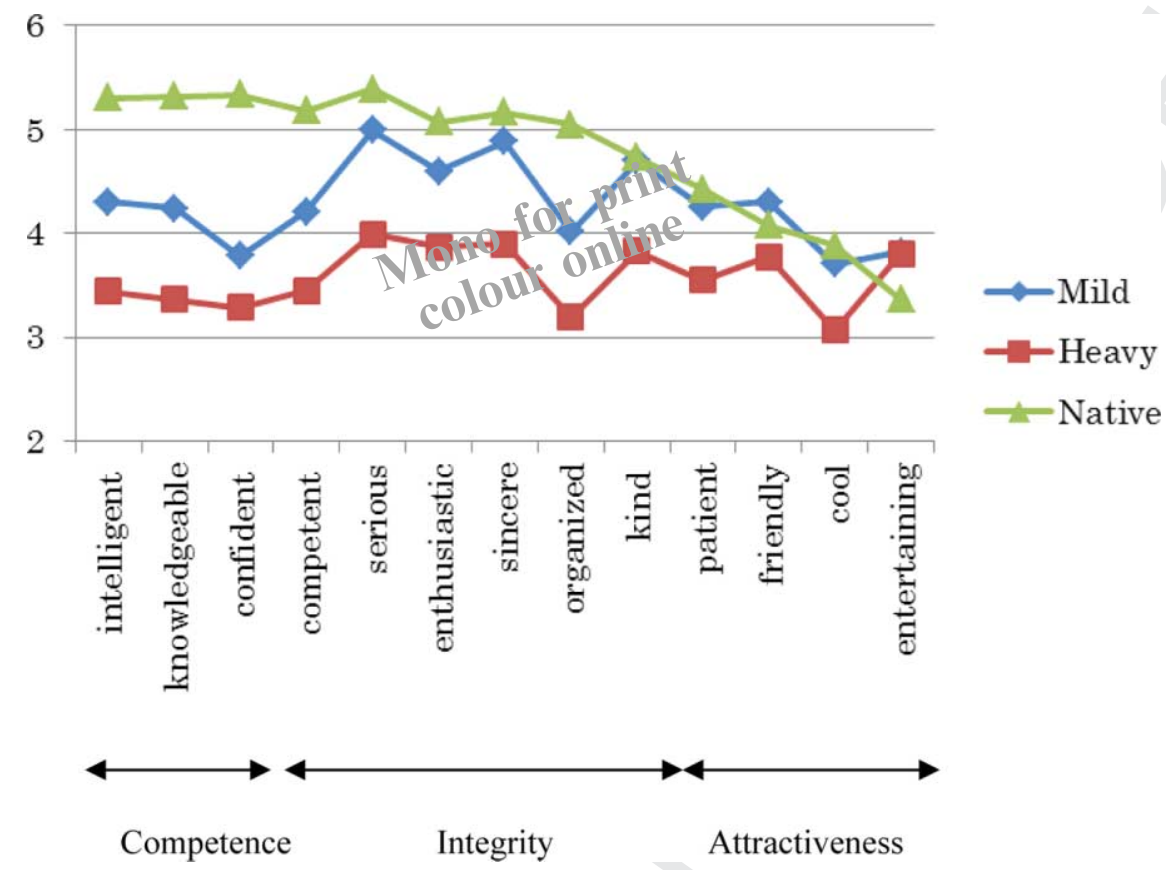

Figure 2. Group R participants' average score for each speaker's likely character.

university degree. Tables 7 and 8 show the number of participants who identified likely occupations, with high and low status, respectively, for the three groups of speakers.

These tables reflect the results shown in Figures 1 and 2. High-status occupations were attributed most frequently to native speakers and least frequently to non-native speakers with heavily accented speech. The ratio of participants who rated heavily accented non-native speakers as having a low status job was slightly higher in Group R (55 vs. $61 \%)$.

\section{Discussion and conclusion}

This study explored the attitude of Japanese students towards foreign-accented Japanese exclusively on the basis of sound and without visual or other sensory cues. Contrary to the prediction that Japanese people will be tolerant of foreign accents due to the concept that Japanese is a unique language, the results indicate that Japanese students did not show favourable attitudes towards unseen foreign-accented speakers, and evaluated accented speech negatively, as reported in previous studies on native English speakers' appreciation of accented English. The heavier the accent was, the lower the evaluation score became. Scores for accented speech were as high as the ones for native speech only in social attractiveness, which corresponds with the

Table 7. Group M participants' evaluations of speakers' likely job status.

\begin{tabular}{lccc}
\hline & High status & Low status & No reply \\
\hline Japanese-native & $70 \%(81)$ & $13 \%(15)$ & $17 \%(20)$ \\
Non-native slightly accented & $44 \%(51)$ & $42 \%(49)$ & $14 \%(16)$ \\
Non-native heavily accented & $28 \%(32)$ & $55 \%(64)$ & $17 \%(20)$ \\
\hline
\end{tabular}


Table 8. Group R participants' evaluations of speakers' likely job status.

\begin{tabular}{lccr}
\hline & High status & Low status & No reply \\
\hline Japanese-native & $73 \%(96)$ & $21 \%(28)$ & $6 \%(8)$ \\
Non-native slightly accented & $44 \%(58)$ & $48 \%(63)$ & $8 \%(11)$ \\
Non-native heavily accented & $27 \%(35)$ & $61 \%(81)$ & $12 \%(16)$ \\
\hline
\end{tabular}

findings of the previous studies. This tendency was seen equally in the responses of students who live in a metropolitan area and those who live in a rural area. The result implies that without visual cues and other information, Japanese native speakers negatively evaluate accented Japanese speech. The participants intuitively formed a better impression of speakers with fluent native speech than with non-native speech, as do people in English-speaking countries. Another explanation could be found in a change of the attitude towards accented Japanese in the young generation of Japanese. Whether the results reflect recent trends in Japanese society could be confirmed by conducting a similar survey on an older generation.

Japanese people are often impressed with foreigners who can speak Japanese and praise the speakers' efforts even they speak only a short phrase (Neustupny 1986). This was a perception shared among foreigners who have been to Japan. The results of the current study, however, did not support these observations, which suggest that Japanese people's positive evaluation of Japanese speech by foreign speakers might occur only when the people meet face-to-face or the listener is able to see the speaker. However, this point needs to be confirmed by using a similar task accompanied by a visual representation.

It was originally assumed that people in a rural area, Group $\mathrm{R}$, have more respect for foreigners who speak Japanese than do people living in metropolitan areas, Group M, due to the expectation that foreigners cannot speak Japanese fluently. However, the opposite was true. People in the metropolitan area, who come across foreigners more often, have slightly more flexible views towards accented speakers, whereas Group R, students who never or rarely met foreigners, held more traditional views such as 'highly fluent speakers are definitely native speakers' (shown in Table 1) and 'strongly accented speakers have low-status jobs' (Lindemann 2003). Group M indicated higher possibility that a highly fluent speaker of Japanese could be a foreigner (see Tables 7 and 8). The university major students in Group $M$ was international relations and thus this group's participants may well have greater interest in speakers with different language backgrounds than the participants in Group $\mathrm{R}$ whose major was dietetics. Overall, the finding of a previous study that familiarity nurtures favourable attitude towards accents was confirmed in this study as well.

Second-language learners of English all over the world strive to be fluent speakers and face discrimination when their foreign accent is evident in their speech (Rubin 1992). Second-language learners of English tend to victimise themselves and sometimes become pessimistic about their status as a non-native speaker. This study suggests that if the native tongue of the listener is spoken by non-native speakers, the listener will easily notice the speaker's accent and evaluate it negatively if no information is given about the speaker's background or the context of the discussion, also in a language other than English. As English has become a world language through the last century, accented English and its speakers tend to be under the spotlight and scrutiny of researchers more often than other languages. The results of 
this study provide evidence that discrimination against foreign accent, a social phenomenon reported in English-speaking society, is merely a natural reaction that speakers of any language can have towards non-native speakers, and it can be observed in other language communities.

Often people uphold unfavourable stereotypes of other people with a language and culture different from their own, and such people are often treated with suspicion. This phenomenon can be seen in any society and seems to be difficult to eradicate. One way of reducing negative stereotyping is to increase the amount of communication between native and non-native speakers of the target language. Currently in Japanese society, opportunities for the young generation of university students to mix with international students on campus are increasing. The role of education, and language education in particular, is becoming more important than ever before to teach people to understand each other beyond their linguistic and racial differences, which are only superficial.

In future research, the collection of speech samples will be extended to female non-native speakers and to Korean or Chinese accented speakers. The enlarged collection will be used to survey a different generation of participants, as we make further efforts to deepen understanding of the attitude of Japanese people towards foreign-accented speakers of Japanese.

\section{Acknowledgements}

I would like to thank Martin Holda and Setsuko Shirono for the data collection, and three anonymous reviewers for their helpful comments.

\section{References}

Ball, P. 1983. Stereotypes of Anglo-Saxon and non-Anglo-Saxon accents: Some exploratory Australian studies with the matched guise technique. Language Sciences 5: 163-83.

Bresbahan, M.J., R. Ohashi, R. Nebashi, W.Y. Liu, and S. Morinaga Shearman. 2002. Attitudinal and affective response towards accented English. Language and Communication 22: 171-85.

Callan, V.J., and C. Gallois. 1983. Anglo-Australian attitudes towards immigrants: A review of survey evidence. International Migration Review 17: 120-37.

Callan, V.J., C. Gallois, and P.A. Forbes. 1983. Evaluative reactions to accented English: Ethnicity, sex role, and context. Journal of Cross-Cultural Psychology 14, no. 4: 407-26.

Cargile, A.C., and H. Giles. 1998. Language attitudes toward varieties of English: An American-Japanese context. Journal of Applied Communication Research 26: 338-56.

Carroll, T. 2001. Language planning and language change in Japan. Richmond, VA: Curzon Press.

Chiba, R., H. Matsuura, and A. Yamamoto. 1995. Japanese attitudes towards English accents. World Englishes 14, no. 1: 77-86.

Eisenchlas, S., and C. Tsurutani. 2011. You sound attractive! Perception of accented English in a multilingual environment. Australian Review of Applied Linguistics 34, no. 2: 218-38.

Gass, S., and E.M. Varonis. 1984. The effect of familiarity and comprehensibility of non-native speech. Language Learning 34: 65-89.

Gottlieb, N. 2005. Language and society in Japan. Cambridge: Cambridge University Press.

Homusho (Ministry of Justice). 2012. http://www.moj.go.jp/nyuukokukanri/kouhou/press_ AQ9 030530-1_030530-1.html (accessed May 1, 2012).

AQ10 Iino, M., Y. Ohmura, H. Sugita, and N. Moriyoshi. 2003. Shinsedai no gengagaku. Tokyo: Kuroshio Publishing.

Japan Student Service Organization. 2010. http://www.jasso.go.jp/statistics/intl_student/ data08.html (accessed February 10, 2011). 
Jenkins, J. 2000. The phonology of English as an international language. Hong Kong: Oxford University Press.

Kirkpatrick, A., D. Deterding, and J. Wong. 2008. The international intelligibility of Hong Kong English. World Englishes 27, no. 3/4: 359-77.

Lambert, W.E. 1967. The social psychology of bilingualism. Journal of Social Issues 23: 91109.

Lev-Ari, S., and B. Keysar. 2010. Why don't we believe non-native speakers? The influence of accent on credibility. Journal of Experimental Social Psychology 46, no. 6: 1093-96.

Lindemann, S. 2003. Koreans, Chinese or Indians? Attitudes and ideologies about non-native English speakers in the United States. Journal of Sociolinguistics 7, no. 3: 348-64.

Lippi-Green, R. 1994. Standard language ideology, and discriminatory pretext in the courts. Language in Society 23, no. 2: 163-98.

Long, D. 1999. Mapping non-linguists' evaluations of Japanese language variation. In Handbook of perceptual dialectology, Vol. 1, ed. D.R. Preston, 199-226. Amsterdam: John Benjamins.

McKenzie, R.M. 2008. The role of variety recognition in Japanese university students' attitudes towards English speech varieties. Journal of Multilingual and Multicultural Development 29: 139-53.

McKenzie, R.M. 2010. Social psychology of English as a global language. Dordrecht and New York: Springer.

Morris, M.Y. 2010. Regional stereotypes and the perception of Japanese vowel devoicing. In $A$ reader in sociophonetics, ed. D.R. Preston and N. Niedzielski, 191-202. New York: Mouton de Gruyter.

Munro, M.J. 2003. A primer on accent discrimination in the Canadian context. TESL CANADA Journal 20, no. 2: 38-51.

Munro, M.J., T.M. Derwing, and K. Sato. 2006. Salient accents, covert attitudes: Consciousness raising pre-service second language teachers. Prospect 21, no. 1: 67-79.

Neustupny, J.V. 1986. Communication with foreigners. Tokyo: Iwanami.

Riches, P., and M. Foddy. 1989. Ethnic accent as a status cue. Social Psychology Quarterly 52, no. 3: 197-206.

Rubin, D.L. 1992. Non-language factors affecting undergraduates' judgements of nonnative English-speaking teaching assistants. Research in Higher Education 33, no. 4: 511-31.

Seggie, I., C. Fulmizi, and J. Stewart. 1982. Evaluations of personality traits and employment suitability based on various Australian accents. Australian Journal of Psychology 34: 345-57.

Shibatani, M. 1990. The language of Japan. Cambridge: Cambridge University Press.

Suzuki, T. 1978. Words in context: A Japanese perspective on language and culture. Tokyo: Kodansha.

Tipton, E.K. 2008. Modern Japan. New York: Routledge.

Tokumoto, M., and M. Shibata. 2011. Asian varieties of English: Attitudes towards pronunciation'. World Englishes 30, no. 3: 392-408.

AQ12 Tokyo Shimbun. 2011. http://www.bochao.jp/article/13346282.html (accessed March 30, 2011).

Willcock, H. 2008. The two cultures: Balancing choices and effects - Japan's balancing of the duality to attain cultural revitalization. Forum on Public Policy 4, no. 4: 13-26.

Yashima, T., L. Zenuk-Nishide, and K. Shimizu. 2004. The influence of attitudes and affect on willingness to communicate and second language communication. Language learning 54, no. 1: 119-52.

\section{Appendix 1:}

Participants' speculation about speakers' social status and occupations.

High status Teacher, professor, minister, doctor, nurse (salary man? salaried worker?), librarian, architect, civil servant, priest, computer programmer, prince (royal family), pilot, interpreter, announcer

Low status Singer, entertainer, waiter, chef, athlete, soldier, shop assistant, sales person, fortune-teller, fighter, artist, part-time worker, student*

\footnotetext{
*Student was included in 'Low status' as s/he has not yet obtained a university degree.
} 